\title{
GÉNESIS Y EVOLUCIÓN DE UN PERFIL LITERARIO \\ (PARA UN ESTUDIO DE LA RECEPCIÓN A PARTIR DE LOS ESTRENOS TEATRALES)
}

Assumpta Camps

La recepción de un autor en un país diferente al de su origen se ve condicionada por varios factores que dependen, y no en pequeña medida, del conocimiento del idioma en que se expresa. Las traducciones son, desde este punto de vista, un aspecto importante a considerar en un estudio de estas características. Lo son, también, las referencias al autor presentes en ensayos, artículos de diversa índole, correspondencia varia, etc. Un capítulo especialmente interesante para los autores dramáticos es el estudio de su recepción a partir de los estrenos teatrales de sus obras, ya sean versionadas en la lengua de destino, o presentadas en la lengua original, puesto que se cuenta, en este caso, con la ayuda que proporciona siempre la puesta en escena. Situándonos desde esta perspectiva, nos interesará, así pues, analizar qué obras llegan a conocerse directamente por el público, cuándo se produce tal toma de contacto y en relación a qué otros hechos del contexto cultural y social en los cuales deben inscribirse, y, sobre todo, qué imagen van creando de ese autor. En el caso que nos ocupa, estudiaremos la vía de penetración de D'Annunzio en ámbito catalán a través de los numerosos estrenos de su obra acaecidos hasta la I Guerra Mundial, en líneas generales; unos estrenos que se producen de un modo que podemos considerar prácticamente contemporáneo a los estrenos mundiales de esas mismas piezas. Nos interesa especialmente observar cómo recibe el público catalán, a partir de las críticas teatrales, la producción de D'Annunzio, ya se trate de estrenos en el extranjero o bien en Barcelona, y cómo se va generando, de este modo, un perfil literario de este autor destinado a tener continuidad y trascendencia. Por las características del hecho dramático en sí, estas crónicas y críticas teatrales, aunque en muchas ocasiones sean de menor profundidad y pericia que otras opiniones expresadas sobre el autor en las mismas publicaciones, adquieren, sin embargo, una mayor difusión entre el gran público medianamente culto, cliente habitual de los teatros de la época, contribuyendo a la formación de una imagen que a menudo no se verá alterada, o contrastada, como sería desable, por la lectura directa de las obras, o incluso por el conocimiento del resto de la obra no dramática del autor.

En este proceso de recepción de D'Annunzio, un personaje de primera importancia desde un principio fue el cronista de la actualidad romana del periódico "La Vanguardia", que firmaba con el pseudónimo "Cesare". Fue él quien, por primera vez, a finales de 1897, habló del proyecto de D'Annunzio de levantar, a orillas del Lago Albano, un teatro griego donde poder representar obras de corte clásico -ya fueran traducciones o bien obras modernas 
inspiradas en tragedias griegas, en las cuales, al parecer, se había de manifestar el resurgimiento del "genio latino" y, por extensión, la recuperación de una concepción diferente del hecho teatral, entendido como ceremonia civil y religiosa a la vez-. Cesare insistirá sobre este tema en diversas ocasiones durante los casi siete años que abrazan sus colaboraciones en el periódico barcelonés. Al fin y al cabo, éste era uno de los argumentos de más peso para presentar D'Annunzio en el extranjero como uno de los valores culturales italianos más "exportables", aspecto que desde siempre había preocupado al cronista. Exportable por su valor literario, pero, además, original e innovador, capaz de aportar algo nuevo en el panorama literario europeo finisecular como estandarte de aquel "renacimiento latino" que ya en 1895 anunció y propugnó De Vogüél al presentar, así mismo, D'Annunzio como la figura más importante de ese movimiento. De este modo, cada vez que D'Annunzio se convierte en noticia, bien sea en Italia o en Francia, por el estreno de alguna de sus obras dramáticas, Cesare se ocupa puntualmente de él, en términos generalmente elogiosos, y siempre dentro de estas coordenadas. Hasta el punto de que ante el estreno en varias ciudades italianas de Sogno di un mattino di primavera, interpretada por la Duse, intentará explicar el fracaso como resultado de la testarudez de D'Annunzio por continuar en la línea del teatro simbolista cuando, por el contrario, la vía del renacimiento de la tragedia griega entiende que le había de dar mejores resultados en el futuro. El estreno de La ville morte en el "Théâtre de la Renaissance" de París a principios del 1898 le sirve como pretexto para insistir en ello, al elogiar esa fatalidad clásica, así como la visión pagana del mundo que la tragedia explora como presupuestos, ambos, del nuevo teatro moderno de los pueblos meridionales. Así, con motivo de la polémica que el estreno de La Gioconda suscita el año siguiente, Cesare aprovecha para perfilar a D'Annunzio de nuevo como un autor "neotrágico", capaz de revitalizar el teatro moderno mediante no tan sólo la introducción de la poesía en escena, así como una especial preocupación por los aspectos formales -por lo que él llama su sentido "aristocrático" de la lengua-, sino también por su modo particular de fundir el alma moderna con la antigua: de "modernizar", en fin -si así podemos decirlo-, el sentido trágico griego con las teorías nietzscheanas de la moral del superhombre. Sin embargo, unos años más tarde, ante la batalla campal que suscitó Francesca da Rimini en Italia, Cesare ya no justificará abiertamente a D'Annunzio, aunque continuará defendiendo estos postulados dramáticos: en esa ocasión, si D'Annunzio resulta ser un autor incomprendido por el público es porque se muestra demasiado innovador y atrevido al recuperar la fuerza del instinto y ese vigor oculto en los orígenes de la estirpe latina. Sus escasas concesiones a criterios comerciales son el origen de tantas críticas violentas.

Así las cosas, observamos que D'Annunzio ya tiene, en los albores del siglo, un perfil dramático muy claro en Cataluña; perfil que se irá completando, incluso por parte del mismo Cesare, con comentarios sobre cuál ha de ser la función social asignada a este "nuevo" teatro, con ocasión, por ejemplo, del estreno de La Gioconda (9-I-1900), y, muy especialmente, gracias a la atención que merecerá La Nave, tragedia que, sin embargo, no se

1 E.-M. DE VOGüÉ: La renaissance latine. Gabriele D'Annunzio: poèmes et romans, "Revue des Deux Mondes", 1-I-1895, págs. 187-206. 
llegó a estrenar nunca en Cataluña. Los estrenos de las obras del italiano insisten, a partir de 1900, como veremos más adelante, en esta imagen de un teatro moderno y a la vez muy propio, muy meridional o latino, poético y altamente formalista, que se convertirá, de hecho, en vehículo para la formulación de mitos nacionalistas de corte imperialista, basándose en la recuperación, por vía nietzcheana, del sentido trágico griego. Un teatro que surge, desde el primer momento, como réplica al teatro realista y al vaudeville, y que pretende transformar la concepción dramática del teatro tradicional para el entretenimiento burgués. Hasta el punto que, alrededor de los años 1908-1909, con ocasión del debate abierto en Cataluña sobre la necesidad de un teatro propiamente nacional -catalán-, D'Annunzio pasa a adquirir una funcionalidad y un grado de ejemplaridad nuevo y singular.

La primera toma de contacto del público catalán con la producción dramática dannunziana tiene lugar, de manera espectacular, con la visita de la Duse para el estreno de La Gioconda el 7 de Noviembre de 1900 en el "Teatre Novetats" de Barcelona. El posible "impacto" de la obra se confunde, en esta ocasión, con el entusiasmo que suscitó la presencia de la diva en la ciudad, puesto que los elogios que recibe La Gioconda van, de hecho, dirigidos a la actriz. Es un rasgo característico de determinada prensa, como el periódico "El Diluvio", cuya atención se dirige invariablemente a los actores, en vez de a la obra o al autor. Tan sólo algunas voces desde la revista "Joventut", baluarte modernista del momento, apuestan por D'Annunzio como autor dramático de calidad indiscutible, incluso en abierta polémica con otras publicaciones del mismo signo, como "Pèl \& Ploma", donde Miguel Utrillo confiesa su franca antipatía por el italiano, poeta más que dramaturgo, y Eduardo Marquina expresa sus reticencias ante esa complacencia por la elaboración formal presente en D'Annunzio. En "Joventut", en cambio, el elogio es indiscriminado, sobre todo por parte de uno de sus colaboradores habituales, Salvador Vilaregut. La revista llega, incluso, a presentar, gracias a Celestí Galcerán, la traducción de la Escena IV del Acto I de la tragedia ${ }^{2}$. Sin embargo, La Gioconda recibe en aquella ocasión críticas bastante duras, por parte tanto del público como de algunos críticos. Y por dos motivos: por su estilo recargado en exceso, y por su "inmoralidad". Eso sin negarle la excepcionalidad del montaje, la calidad poética, la excelencia de la interpretación, y la perfección del lenguaje. Hay que añadir que a la Duse, en el papel de Silvia Settala, que acaba sacrificando sus manos para que no se rompa la estatua de su marido, se debe en gran medida la fortuna que el motivo literario -recurrente en D'Annunzio- de las manos femeninas obtuvo en autores como Josep Tharrats o Alfons Maseras.

Sea como fuere, cuando el 16 de Mayo de 1907 la Compañía de Tina di Lorenzo vuelve al "Novetats" con la obra, tan sólo el periódico "La Publicidad" se hace eco del estreno en términos elogiosos. En efecto, "Farfarello", pseudónimo de Rafael Marquina, presentará La Gioconda, junto con La Città Morta y La Figlia di Iorio, como uno de los hitos del teatro moderno, concebido aquí en su dimensión casi religiosa, donde el autor cumple una función de sacerdote de multitudes. Con una prosa de un estilo innegablemente dannunziano,

2 "Joventut", 1-XI-1900. 
"Farfarello" subraya la fuerza creadora -"poética"- del verbo que se manifiesta en la exuberancia formal del italiano, y pone de manifiesto lo que él entiende como la recuperación del sentido trágico en el mundo moderno, industrial y positivista, gracias al triunfo absoluto de la inmortalidad del arte. Sin embargo, otras publicaciones de prestigio y amplia difusión -"El Poble Català", "La Veu de Catalunya", "El Brusi", "La Vanguardia"...ignoran prácticamente el acontecimiento.

Lo cierto es que a partir de la llegada de la Duse a Barcelona en 1900 cualquier estreno de D'Annunzio, ya sea en Cataluña o en el extranjero, merece la atención de la crítica en los primerísimos años del siglo XX. Para bien o para mal. Hay que decir que en pocas ocasiones los juicios son realmente objetivos. Lo más habitual es encontrarnos con que se utiliza a D'Annunzio como estandarte de alguna posición estética defendida -o denostada- a ultranza. Así, por ejemplo, a través de él y del comentario sobre su obra podemos hallar la defensa de un teatro que se propone la recuperación de temas históricos, o bien la explotación de la pasión y la fuerza incontrolada de los intintos, del pathos, en fin, en el escenario; o incluso la propuesta de un resurgimiento del clasicismo, aunque de corte paganizante y "salvaje", no compartido, desde luego, desde otras posiciones más ortodoxas. En este orden de cosas, no debe sorprendernos que las críticas que reciba se acompañen a menudo de una condena de orden estrictamente moral: por la "barbarie" de los temas, por el contraste entre el primitivismo de los comportamientos y el refinamiento de la expresión, por el predominio de los aspectos formales sobre contenido ... El estreno de Francesca da Rimini en el "Teatro Costanzi" de Roma, por ejemplo, suscitará los elogios incondicionales del cronista anónimo de la revista "Auba", por ser una obra de una belleza indiscutible de corte wagneriano. Lo mismo podemos leer expresado, aunque con más reservas, por el cronista de "La Publicidad", y, en líneas generales, también por Xavier Viura, desde "Joventut", quien subraya la explotación del horror para vehicular esa fatalidad griega que el autor persigue en sus tragedias modernas. Pero el comentario más entusiasta de la revista -así como el más documentado, a la vez-, será el de Jeroni Zanné, quien, además, reproducirá la Escena V del Acto I. Zanné añadirá que las críticas recibidas por Francesca... en Italia son, ni más ni menos, que el producto de una moral hipócrita.

Cuando la Compañía de Ferruccio Garavaglia lleve de nuevo la obra a Barcelona, al "Teatre Eldorado", el 7 de Octubre de 1905, las reacciones de la crítica repitirán la situación que veíamos a propósito de La Gioconda. Sin embargo, observamos que queda ya bastante completo por entonces el perfil dramático de D'Annunzio: un autor de teatro poético, con más cualidades líricas que dramáticas, que recrea un lenguaje arcaico y explora el horror que provoca la crueldad, con una mezcla insólita de ferocidad y refinamiento. Y, una vez más, la condena por su artificiosidad y falta de sobriedad en el estilo se relacionará con la condena por inmoralidad -no sólo por los temas, sino también por su tratamiento y por la actitud misma del autor ante el lenguaje-. Con una particularidad, que observamos en el comentarista de ese gran periódico conservador de la época, "La Veu de Catalunya": el error de D'Annunzio en esta ocasión -error que es responsable de la pérdida del tono trágico que, sin embargo, el autor persigue en los personajes-, se debe buscar, precisamente, en su 
pretensión de recrear un tema como el de los amores entre Paolo y Francesca, inmortalizado por un clásico como Dante. En definitiva, lo que se cuestiona aquí es, ni más ni menos, que la revisión a que D'Annunzio somete un tema de la tradición literaria sobradamente conocido, con el propósito de hacer una versión moderna del mismo. Esta crítica, así pues, deberíamos hacerla extensiva al conjunto del proyecto dannunziano de recuperación de la tragedia griega concebida como experiencia de renovación teatral.

La Figlia di Iorio, estrenada por la Compañía siciliana de Giovanni Grasso el 18-I-1907 en el "Novetats" resulta ser, con mucho, la tragedia de D'Annunzio que más admiración suscitó en Cataluña. Ya se hablaba de ella en 1905, en ocasión de una lectura acaecida en Roma, en 1904, ante unos amigos ${ }^{3}$, como de una obra de belleza insólita por su combinación de barbarie primitiva y lujuria, con un lenguaje y un tratamiento dramático muy efectivos. En aquella ocasión, se ofrecía también el argumento de la tragedia, y se la elogiaba ni más ni menos que como un intento de recuperación de los valores ancestrales de la raza a través de la exploración en un misticismo paganizante, de raíz pánica. Tanta fue la expectación que suscitó, que incluso podemos encontrar, ese mismo año, el comentario casual de un simple fait divers enfocado, precisamente, desde la óptica de la tragedia dannunziana ${ }^{4}$. Esa es la tónica que sigue la crítica con motivo de su estreno en 1907. Sólo que, en esta ocasión, todos coinciden en resaltar el equilibrio alcanzado en esta obra entre las cualidades teatrales y las poéticas. El único problema es que, mientras para algunos ese "furor dionisíaco" resulta ser una cualidad positiva, para otros, en cambio, se muestra como el peor y más peligroso de sus "venenos" morales: porque hace agradable al espectador, bajo unos versos perfectos, esculpidos de manera "diabólica", la "perversidad escandalosa" del planteamiento de la acción teatral (véase, al respecto, "La Veu de Catalunya" o la revista "Empori"). Dos años más tarde, la Compañía de Mimí Aguglia repondrá La Figlia di Iorio en el "Teatre Novetats" de Barcelona. Entonces "La Veu..." la presentará como una obra desigual, llena de defectos formales, que se salva tan sólo por la interpretación genial de la Aguglia en el papel de Mila di Codra, ya que el efecto que produce en el público resulta excesivo en su pretensión de acumular horror para causar un miedo casi sagrado. No faltarán a la cita, claro están, los dannunzianos incondicionales de "Joventut Teatral" o "Teatràlia", dos revistas dedicadas exclusivamente a los comentarios del mundo del espectáculo en general.

Durante la temporada 1907/8, la Compañía catalana del "Teatre Intim" de Adrià Gual llevó a escena por primera vez una obra de D'Annunzio, La Fiaccola sotto il Moggio, traducida al catalán por ese gran admirador del autor italiano, Salvador Vilaregut, como "La LLàntia del Odi". Fue estrenada en el "Teatre Català Romea" el 10-I-1908. La mayor parte de las publicaciones periódicas recogieron este hecho singular manifestando una gran expectación por este primer intento de trasladar D'Annunzio al catalán, al cual se añadía el esfuerzo de llevarlo a escena. Algunos, como cabía esperar, se mostraron muy poco

\footnotetext{
3 "La Vanguardia", 14-I-1905.

4 Muñiz de Quevedo: Honor silvestre (¿Figlia di Iorio?), "La Publicidad", 21-II-1905.
} 
entusiastas con el resultado, criticando abiertamente la traducción de Vilaregut. Entre los defensores, una de las revistas que apostó con más fuerza por la carta de D'Annunzio en catalán fue "De Tots Colors", que hizo una gran presentación de la traducción, incluida en el primer número de su biblioteca popular. La revista, por otra parte, no escaseó en alabanzas al montaje y al estreno, y se esforzó, además, por presentar a D'Annunzio como un autor italiano de prestigio "académico": como un ejemplo, en fin, de como un artista moderno y de talla internacional no tiene necesariamente que mostrarse como un escritor inmerso en la marginalidad cultural de una bohème más bien negra y miserable, como la que propugnaban por entonces algunos de los dannunzianos más fervientes en Cataluña.

"La Publicidad" secundó completamente el proyecto de Gual como una vía teatral abierta a la recuperación del sentido trágico griego, como cabía esperar. Añadamos, sin embargo, que para "Farfarello", D'Annunzio -o el "Magnífico Perverso", como él le llama en más de una ocasión- pasaba a constituirse en el único gran poeta trágico del momento, tanto por sus cualidades poéticas, como, sobre todo, "por su gesto perverso" -que, en nuestra opinión, cabe entender, si es que hay que entenderlo de algún modo, en sentido nietzscheano-. Con todo, D'Annunzio había hecho en La Fiaccola..., al parecer, concesiones a la teatralidad comercial y al gran público, según el inefable "Farfarello", puesto que había pintado un odio no sublime sino simplemente criminal, a través de un lenguaje que no llegaba a alcanzar las alturas poéticas insondables de otras ocasiones. Esta crítica a la falta de grandeza trágica y a la mediocridad del lenguaje se repite, por cierto, en "La Vanguardia", mientras que, por su parte, el comentarista anónimo de "La Escena Catalana" subrayará el mérito del italiano al infundir pasión y cuerpo a "lo que no es más que una huella histórica, que una débil tradición, que una sutil leyenda", en la línea seguida ya por los griegos y más tarde por Shakespeare, y gracias al estilo empleado por el autor, lleno de ampulosidades de lenguaje y entusiasmos infinitos, "que tanto influyen, sobre todo, en la prosa de nuestros jóvenes". Y, en efecto, D'Annunzio, a través de sus tragedias se constituye por entonces, aún más, quizá, que a través de su inmensa y rica obra poética, en un modelo de primer orden para los primeros intentos de creación de una prosa poética en Cataluña.

El valor "pedagógico" que comportaba llevar a D'Annunzio a la escena catalana es lo que más valora un crítico como López-Picó en su comentario de "La Veu de Catalunya", donde se expresa en los términos en que lo hará más tarde en sus colaboraciones para la revista "Teatràlia" sobre la necesidad de un teatro poético catalán. Sin embargo, y a pesar del éxito innegable de esta tragedia, aparecen ya voces que presentan a D'Annunzio como un valor dramático caduco ${ }^{5}$. Y no faltan, así mismo, publicaciones donde la obra se contempla con notables reticencias: "Ilustració Catalana" y "Diario de Barcelona" comentan que la traducción de Vilaregut es vulgar y somete el texto de D'Annunzio a una prosaización que lo descalifica como teatro "poético". Con todo, el aspecto más criticable parece ser que en $L a$ Fiaccola... D'Annunzio no hace sino repetirse a sí mismo, de un modo que cae en el melodrama en su intención de conmover al lector a través del pathos y las emociones fuertes

5 Así lo leemos, por ejemplo, en la crónica de "Arricus": Cròniques de Roma, "La Veu de Catalunya", 25-I1908. 
originadas en el horror, esa fuente de un goce que no puede ser jamás "puramente" estético para el comentarista. El "Almanaque" del mismo periódico para ese año insistirá en que se trata de una obra "poco recomendable" desde un punto de vista social.

Cuando Ferruccio Garavaglia lleve, de nuevo, la obra a Barcelona a finales de Mayo de 1909, al "Teatre Eldorado" para ser exactos, La Fiaccola... ya merecerá más bien poca atención: tan sólo hallamos la noticia de la representación la noche del beneficio de la compañía ${ }^{6}$ y la publicación (en la misma revista, el 27-VIII-1909), de A la Regina Sangro, de J.-M. Muntanyà, donde se recrea otra de las muchas heroínas dannunzianas de mirada fulminante: es decir, una belle dame sans merci.

Una de las últimas tragedias de D'Annunzio que el público catalán pudo ver representada, Piú che l'amore, fue un fracaso rotundo para prácticamente todo el mundo. Al estrenarse por parte de la Compañía italiana Dora Baldanello en el "Teatre Eldorado" el 28 de Mayo de 1909 -en la misma temporada teatral que La Fiaccola..., así pues- la crítica coincidió de modo unánime en señalar que se trataba de una obra que no estaba a la altura de las otras del dramaturgo italiano, a pesar de ser presentada como el plato fuerte de la tournée de la compañía. Incluso "Farfarello", siempre tan entusiasta con D'Annunzio, como hemos podido comprobar, comentará, en esta ocasión, que la obra le resulta decepcionante: no alcanza la talla trágica esperada, es inverosímil, presenta errores formales y, sobre todo, una tesis errónea, puesto que el autor coloca la fuerza del destino por encima del amor. En conjunto, el "Magnífico Perverso" había ofrecido al público, en aquella ocasión, una tragedia débil desde el punto de vista estético y moral, que ni siquiera la interpretación de los actores fue capaz de salvar. Eso sí, con la opulencia verbal que le caracterizaba. La condena de orden ético-estético se repite en "La Veu de Catalunya": es una obra lenta, de escaso ritmo, que ofende al público puesto que parece una tomadura de pelo del autor. Por su parte, el fracaso mundial de la obra en su estreno el 1907 es todo lo que se entretiene en recoger el comentarista de la "Ilustració Catalana".

La Compañía de Mimí Aguglia, sin embargo, volverá a llevar a escena esta tragedia el año siguiente -el 22 y 24 de octubre de 1909, para ser exactos-, en el "Teatre Novetats", durante una escapada de diez funciones que hizo la actriz desde París, sin demasiado éxito, por cierto, ya que, al parecer, "el primitivismo de este tipo de teatro ya no gustaba al público catalán"7.

Sin embargo, hay que decir que la tragedia que mereció, y con mucho, más atención, a pesar de que no llegó a los escenarios barceloneses (al "Teatre Català Romea", en concreto) hasta la temporada 1922-1923 -en un contexto algo diferente, así pues-, fue La Città Morta. Ya en 1898, poco después de su estreno mundial en París -y en francés-, Joan Pérez-Jorba se hizo puntualmente eco del evento en la revista "Catalònia", no en términos demasiado elogiosos, bien es cierto, pero subrayando, aún con todo, el valor de D'Annunzio como autor que marcaba un rumbo nuevo, con su mezcla de paganismo, barbarie y

6 "De Tots Colors", 4-VI-1909.

7 "Ilustració Catalana", 24-X-1909. 
nietzscheanismo, observable más en su prosa -véanse, al respecto, las parábolas, que el crítico catalán tuvo ocasión de leer en "La Nuova Antologia"8)- que en esta tragedia. La importancia que adquirió La Città... obedece, de un modo muy especial, a su contemporaneidad respecto a las primeras muestras de teatro de corte clasicizante que se dan por entonces en Cataluña, así como al impacto del llamado "movimiento latinista", en boga en Francia en los últimos años del siglo, a través del cual se pretende introducir desde el país vecino una renovación del teatro finisecular de corte simbolista. La admiración por $L a$ Città... da lugar a una serie de traducciones en catalán, todas ellas inéditas y sin estrenar. Son conocidas las de Narcís Serradell -cuyo manuscrito se halla en la Biblioteca-Museo del "Institut del Teatre" de Barcelona-, que, según parece, es de 1899; el proyecto de una traducción de Miquel Ventura, con casi absoluta seguridad de 1898 (según se desprende de su artículo Moviment intel.lectual de Cathalunya", "La Nova Cathalunya" (Reus), 27-III1898); y la traducción de Joan Rosselló de Son Fortesa, sin fecha, que Damià Ferrà-Ponç ya inventarió en su momento9 ${ }^{9}$ y que la correspondencia de su autor con Miquel Costa i Llobera nos ayuda a situar ahí por los años 1906-7. Añadiremos, por nuestra parte, la traducción incompleta e inédita -de tan sólo la Escena I del Acto I-, hecha por el gerundense Josep Tharrats, con fecha de 1910, y que se conserva en un manuscrito del archivo familiar de la familia Tharrats; traducción que surge en un contexto muy preciso, de modo que se inscribe de lleno en el debate que tiene lugar en Cataluña por estas fechas sobre la oportunidad -y necesidad- de un teatro poético no tan sólo en catalán sino propiamente catalán.

A través de la prensa podemos seguir, como hemos intentado mostrar, la génesis y evolución del perfil de D'Annunzio en Cataluña, analizando la parábola de aceptación entre nosotros de la aportación dannunziana al teatro finisecular. Las características de su producción son, desde un principio las siguientes: se trata de un teatro poético, de gran refinamiento formal, cuya influencia alcanzará a los numerosos experimentos catalanes de prosa poética del momento; un teatro que muestra una singular innovación frente al teatro de corte maeterlinckiano ampliamente difundido en la época, por su pretendida recuperación de la tragedia griega. Esta vía, ofrecida como derivación de la concepción teatral simbolista y del drama lírico wagneriano, se combina con la recepción, en la época, de las teorías nietzscheanas, así como con el movimiento de resurgimiento de los pueblos meridionales de Europa, que hallan en la tradición clásica, un camino para reencontrar sus orígenes culturales. La reivindicación de latinismo se revestirá, así pues, al menos en Cataluña, y de la mano de esa defensa de D'Annunzio -emprendida durante esos primeros años de siglo desde ciertos ámbitos culturales- visto como un autor teatral "moderno", de una sutil elaboración de toda una mitología nacionalista que acabará teniendo, con el tiempo, una notable trascendencia cultural.

\footnotetext{
${ }^{8}$ La Parabola delle vergini fatue e delle vergini prudenti, "La Nuova Antologia" (Roma), vol. 63, fasc. XXIV (16-XII-1897), págs. 701-9 y La Parabola dell'uomo ricco e del povero Lazzaro, vol. 72, fasc. 625 (1-I-1898), págs. 3-15.

9 Véase Enric Gallén: El Teatre, en Historia de la Literatura Catalana.- Barcelona, Ariel, vol. VIII, 1986.
} 